\title{
IMPLEMENTASI ALGORITMA GENETIKA UNTUK PREDIKSI PENYAKIT AUTOIMUN
}

\author{
${ }^{1)}$ Debi Setiawan, ${ }^{2)}$ Ramalia Noratama Putri, ${ }^{3)}$ Reni Suryanita \\ ${ }^{1)}$ STMIK Amik Riau, Program Studi Teknik Informatika, ${ }^{2}$ Sekolah Tinggi Ilmu Komputer Pelita Indonesia, \\ Program Studi Sistem Informasi, ${ }^{3}$ Universitas Negri Riau, Program Studi Teknik Sipil, \\ ${ }^{1} \mathrm{Jln}$. Purwodadi Indah KM.10 \\ 2 Jl. Ahmad Yani No 82-84-88 \\ ${ }^{3}$ Kampus Bina Widya KM 12.5, Simpang Baru, Tampan, Kota Pekanbaru \\ E-Mail : 'debisetiawan@stmik-amik riau.ac.id, ${ }^{2}$ ramalia.noratamaputri@lecturer.pelitaindonesia.ac.id, \\ ${ }^{3}$ reni.suryanita@eng.unri.ac.id
}

\begin{abstract}
ABSTRAK
Penyakit autoimun merupakan penyakit yang tidak menular, namun penyakit yang mematikan. Jumlah pasien yang meninggal akibat penyakit autoimun di tahun 2016 adalah 550 kematian. Tingginya angka kematian akibat autoimun karena sulitnnya diagnosa penyakit autoimun. WHO menyatakan 5 juta orang di dunia menderita lupus, sedangkan di Indonesia jumlahnya mencapai 200 ribu orang. Untuk itu diperlukannya prediksi dalam diagnosa penyakit autoimun. Algoritma yang digunakan dalam penelitian ini adalah algoritma genetika. Tujuan dari penelitian ini adalah memprediksi penyakit autoimun dengan algoritma genetika sehingga dokter spesialis penyakit dalam dapat mendeteksi penyakit autoimun secara dini. Data yang digunakan dalam penelitian ini adalah data pasien penyakit dalam selama bulan Agustus Tahun 2018 di rumah sakit Arifin Ahmad Provinsi Riau Kota Pekanbaru. Hasil dari penelitian ini adalah terindentifikasi penyakit auotoimun atau tidak pada pasien.
\end{abstract}

Kata Kunci: Autoimun, Prediksi Autoimun, Genetika, Kromosom, Fitnees

\begin{abstract}
Autoimmune disease is a non-communicable disease, but a deadly disease. The number of patients who died from autoimmune diseases in 2016 was 550 deaths. The high mortality rate due to autoimmune due to the difficulty of diagnosing autoimmune diseases. WHO states that 5 million people in the world suffer from lupus, while in Indonesia the number reaches 200 thousand people. For this reason, predictions are needed in the diagnosis of autoimmune diseases. The algorithm used in this study is a genetic algorithm. The aim of this study is to predict autoimmune diseases with genetic algorithms so that internal medicine specialists can detect autoimmune diseases early. The data used in this study is data on internal medicine patients during the month of August 2018 at Arifin Ahmad Hospital, Riau Province, Pekanbaru City. The results of this study were identified as autoimmune disease or not in patients.
\end{abstract}

Keywords: Autoimmune, Autoimmune Prediction, Genetics, Chromosomes, Fitnees

\section{PENDAHULUAN}

Penyakit autoimun merupakan penyakit yang sulit untuk didiagnosa, karena gejala dari penyakit autoimun mirip dengan penyakit lain. Selain dari gejala yang hampir mirip dengan penyakit lain, penyakit autoimun juga penyakit yang kurang populer dari penyakit kanker. Tahun 2016 terjadi peningkatan angka kematian akibat penyakit autoimun yaitu 550 orang berdasarkan SIRS online, Ditjen Pelayanan Kesehatan, Kementrian Kesehatan 2017[1]. Mengenai peningkatan jumlah penderita penyakit autoimun telah menjadi perhatian di seluruh dunia[2]. Menurut data WHO sekitar 5 juta orang di dunia menderita lupus, sedangkan di Indonesia jumlahnya mencapai 200 ribu orang. Untuk itu diperlukannya prediksi dalam diagnosa penyakit autoimun.

Algoritma Genetika adalah teknik pencarian heuristik yang didasarkan pada gagasan evolusi seleksi alam dan genetik. Algoritma ini memanfaatkan proses seleksi alamiah yang dikenal dengan proses evolusi. Dalam proses evolusi, individu secara terusmenerus mengalami perubahan gen untuk 
menyesuaikan dengan lingkungan hidupnya, hanya individu yang kuat yang mampu bertahan[3].

Penelitian ini didukung oleh penelitipeneliti sebelumnya dalam jurnal Penerapan Metode Neural Network Berbasis Algoritma Genetika Untuk Prediksi Penyakit Kanker Payudara membuktikan bahwa algoritma genetika dapat melakukan prediksi, dengan nilai akurasi 96.85\%[4]. Pada jurnal Implementasi Algoritma Genetika untuk Memprediksi Waktu dan Biaya Pengerjaan Proyek dan Kontruksi menyimpulkan bahwa algoritma genetika dapat memprediksi waktu dan biaya proyek kontruksi berdasarkan luas tanah yang di input dan pemilihan kromosom dengan nilai akurasi $98.72 \%$ [5]. Kemudian pada Jurnal Optimasi Algoritma Naïve Bayes dengan Menggunakan Algoritma Genetika untuk Prediksi Kesuburan (Fertility) peneliti sebelumnya menyimpulkan bahwa algoritma genetika dapat meningkatkan akurasi prediksi dari $97.66 \%$ menjadi $99.33 \%$ [6].

Berdasarkan latar belakang yang telah dijelaskan, maka rumusan masalah penelitian ini yaitu bagaimana menerapkan algoritma genetika dalam prediksi penyakit autoimun yang dapat memberikan hasil yang akurat sehingga penyakit auoimun dapat terdeteksi secara dini. Untuk mendapatkan hasil yang baik penelitian ini memiliki batasan masalah yaitu, penelitian ini menggunakan algortima genetika dalam prediksi penyakit autoimun dengan menggunakan data pasien penyakit dalam RSUD Arifin Ahmad Pekanbaru

\section{Algoritma Genetika}

Algortima Genetika merupakan suatu algoritma heuristic yang didasarkan atas mekanisme evolusi biologis[7]. Keberagamanan pada evolusi biologis adalah variasi dari kromosom antar individu organisme. Variasi kromosom ini akan mempengaruhi laju produksi dan tingkat kemampuan organisme untuk hidup. Pada dasarnya terdapat 4 kondisi yang sangat mempengaruhi proses evolusi, yaitu :

1. Kemampuan organisme untuk melakukan reproduksi

2. Keberadaan populasi organisme yang biasa melakuakn reproduksi

3. Keberagaman organisme dalam suatu populasi

4. Perbedaan kemampuan untuk bertahan hidup

Kontruksi dasar dari Algoritma Genetika adalah sebagai berikut[7]:

1. Pendefinisian Kromosom

2. Pendefinisian fungsi fitness

3. Membangkitkan sebuah populasi awal

4. Reproduksi

5. Crossover

6. Mutasi

\section{Siklus Algoritma Genetika}

Siklus Algortima Genetika pertama kali dikenalkan oleh Davidd Golberg, dimana gambaran siklus tersebut dapat di lihat pada Gambar berikut.

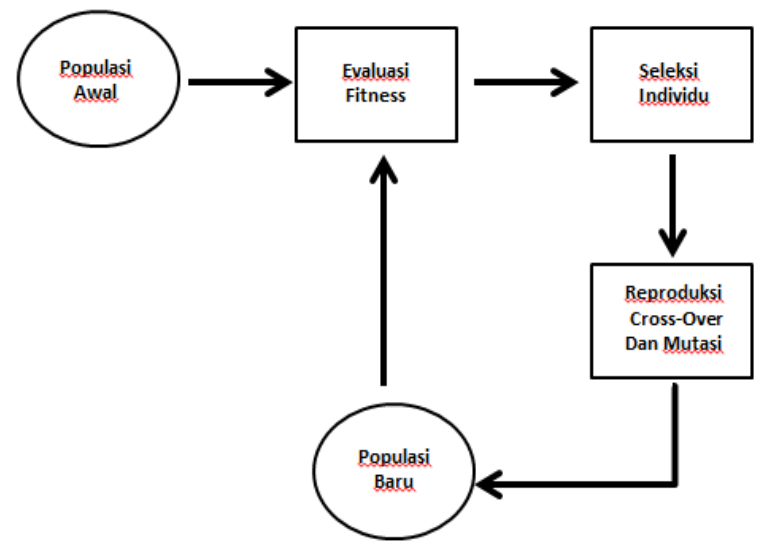

Gambar 2. Siklus Algoritma Genetika dan David Golberg

Siklus ini kemudian diperbaiki oleh beberapa ilmuwan yang mengembangkan 
algortima genetika, yaitu Zbigniew Michalewicz dengan menambahkan operator elitism dan membalik proses seleksi setelah reproduksi.

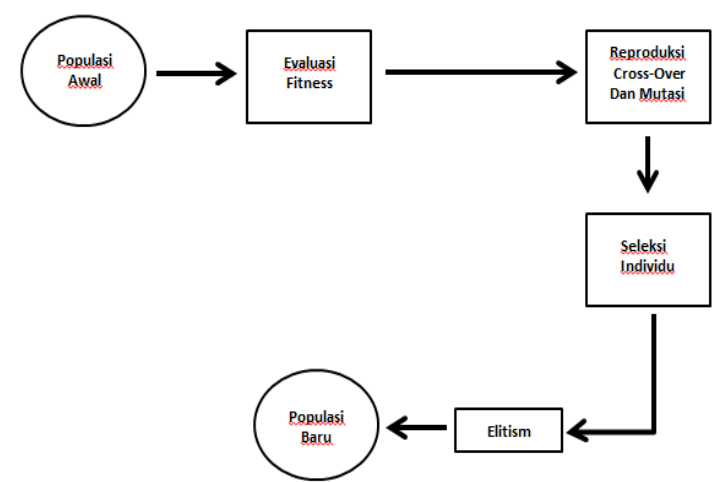

Gambar 3. Siklus Algoritma Genetika Oleh Zbigniew Michalewicz

\section{METODE}

Rangkaian untuk Menyelesaikan masalah dalam penelitian ini adalah :

\section{Mengumpulkan data}

Quesitioner berkaitan dengan angket yang kita berikan kepada pasien penyakit dalam di RSUD Arifin Ahmad pekanbaru, terkait apa saja yang keluhan yang dialami selama beberapa minggu. Pada questioner kita berikan skala 1-3, 3=ya, 2=mungkin 1=tidak sebagai patokan apakah masyarakat memang terindikasi penyakit Autoimun

Tabel 1. Questioner Penyakit Autoimun

\begin{tabular}{ll}
\hline No & Pertanyaan \\
\hline 1 & $\begin{array}{l}\text { Apakah beberapa hari ini } \\
\text { bapak/ibu mengalami rasa ngilu } \\
\text { pada pegelangan sendi? }\end{array}$
\end{tabular}

2 Apakah beberapa hari ini bapak/ibu mengalami lemah pada Otot?

3 Apakah beberapa hari ini bapak/ibu mudah mendapatkan

$4 \quad$ serangan penyakit? Apakah bapak/ibu tidak tahan
5 terhadap cuaca dingin atau

$6 \quad$ sensitive terhadap cuaca panas? Apakah bapak/ibu mengidap

$7 \quad$ alergi kulit

8 Apakah bapak ibu merasakan lelah berkepanjangan?

9 Apakah bapak/ibu merasakan

10 insomnia?

Apakah bapak ibu merasa

11 kurang enak badan seperti demam ringan?

Seringkah ibu berkeringat

12 dimalam hari?

Apakah bapak ibu beberapa hari

13 ini mengalami mati rasa

14 ditangan dan dikaki?

Apakah bapak/ibu ada berkunjung ke dokter dan

15 memeriksa tekanan darah? apakah tekanan darah bapak ibu rendah?

16 Apakah bapak/ibu mengalami

17 (tremor) atau getaran atau

18 menggigil yang terjadi secara

19 tidak sadar? Apakah bapak ibu sering

20 mengalami mata kering?

21 Apakah bapak atau ibu mengalami kehilangan atau

22 penurunan berat badan yang drastis dalam beberapa bulan 23 ini?

Apakah bapak ibu mengalami

24 rambut rontok?

Apakah bapak ibu mengalami mulut kering?

Apakah bapak/ibu merasakan napas pendek?

Apakah bapak/ibu merasakan rasa sakit dan karam ditulang belakang?

Apakah bapak/ibu merasakan 
jantung berdebar tidak wajar?

Apakah bapak ibu merasakan pusing yang berkepanjangan?

Apakah bapak/ibu merasakan Depresi?

Apakah bapak/ibu sulit konsentrasi dan memori terganggu?

Apakah bapak/ibu mengalami pembengkakan pada tungkai kaki?

Apakah bapak/ibu mengalami Pembengkakan mata kaki dan wajah?

\section{Proses Prediksi Algoritma Genetika}

Proses decoding dan encoding

Hal ini berfungsi untuk membuat kode nilai gen dari masing-masing variabel yang mengisi untuk pembentuk individu. Proses yang pertama adalah Pengkodean (Encoding) ini dibagi menjadi tiga jenis bilangan yang dapat dikodekan yaitu untuk

\section{Bilangan real}

$$
X=r_{b}+\left(r_{a}-r_{b}\right) g
$$

1. Bilangan diskrit decimal

$$
\begin{gathered}
x=r_{b}+\left(r_{a c}-r_{b}\right)\left(g_{1} X 10^{-1}+g_{2} X 10^{-2}\right. \\
+\cdots+g_{N} X 10^{-N}
\end{gathered}
$$

2. Bilangan biner

$$
\begin{aligned}
& X=r_{b}+\left(r_{a c}-r_{b}\right)\left(g_{1} X 2+\right. \\
& g_{2} X 2^{-2}+\cdots+g_{N} X 2^{-N}
\end{aligned}
$$

Proses pendekodean (decoding) pembentuk individu agar nilainya tidak melebihi range yang telah ditentukan, dan sebagai nilai variable yang akan dicari sebagai solusi pemecahan permasalahan pada penelitian ini.

\subsection{Penentuan jumlah individu}

Jumlah individu disini berarti jumlah sampel

variable yang digunakan,

2.2 Proses pembangkitan populasi awal

Proses pembangkitan populasi awal dilakukan berdasarkan jumlah individu yang diambil secara random atau acak.

2.3 Proses penentuan nilai dari fungsi tujuan atau nilai fitness

Nilai fitness sama dengan nilai penentu dari fungsi tujuan. Jika dicari nilai maksimal maka nilai fitness dari fungsi itu sendiri, tetapi jika yang dibutuhkan adalah nilai minimal maka nilai fitness merupakan invers dari nilai fungsi itu sendiri. Rumus proses invers adalah

$$
\text { Fitness }=C-f(x) \text { atau fitness }=\frac{c}{f(x)+\varepsilon}
$$

2.1 Pemindahan individu dengan nilai tertinggi (Elitisme)

Untuk menghindari kerusakan atau dengan kata lain nilai fitnessnya tidak turun selama proses silang atau mutasi maka

2.4 Proses seleksi digunakan untuk menentukan nilai optimal local

Untuk menghindari konvergensi premature akibat terjadinya pemindahan optimum local maka dibuatlah mekanisme yang disebut linier fitness rangking (LFR). Tujuan dari mekanisme ini sebenarnya adalah untuk melakukan penskalaan nilai-nilai fitness dengan menggunakan persamaan berikut.

$$
\operatorname{LFR}(\hat{i})=f_{(\max )-} f_{(\min )} \frac{R(i)-1}{N-1}
$$

2.5 Proses cross over atau pemindahan silang

Proses pindah silang ini dilakukan untuk individu yang mengarah pada solusi 
optimal.

\subsection{Proses mutasi}

Proses mutasi dilakukan untuk semua gen yang terdapat pada individu.

\subsection{Penggantian populasi}

Proses ini merupakan proses terakhir yang dilakukan untuk melakukan proses penggantian populasi yang diambil dari proses pindah silang dan mutasi.

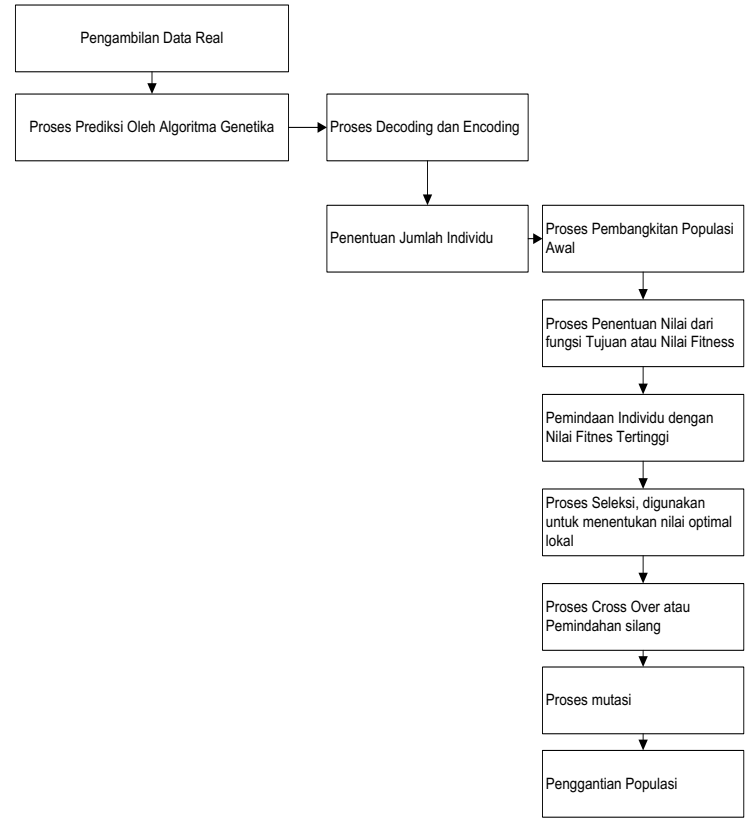

Gambar 1. Metodologi Prediksi Penyakit Autoimun

\section{HASIL}

\section{Pembentukan Cromosome}

Jumlah Populasi awal ada 8 populasi dengan 24 variabel, batasan variable 1-3.

Evaluasi chromosome :

$\mathrm{f}=\mathrm{a}+2 \mathrm{~b}+3 \mathrm{c}+4 \mathrm{~d} \ldots 24 \mathrm{x}=1$ proses seleksi cromosome (1/(1+fungsi_objektif)

Tabel 1. Pembentukan Cromosome

\begin{tabular}{|c|c|c|c|c|c|c|c|c|}
\hline $\begin{array}{l}\text { VARIAB } \\
\text { EL }\end{array}$ & ${ }_{1}^{C}$ & $\mathrm{C} 2$ & C3 & ${ }_{4}^{C}$ & ${ }_{5}^{C}$ & C 6 & C7 & C 8 \\
\hline $\mathbf{A}$ & 1 & 3 & 1 & 1 & 1 & 1 & 1 & 1 \\
\hline B & 3 & 3 & 1 & 1 & 1 & 1 & 1 & 2 \\
\hline C & 1 & 3 & 1 & 2 & 1 & 3 & 3 & 3 \\
\hline D & 1 & 3 & 1 & 1 & 1 & 1 & 1 & 1 \\
\hline $\mathbf{E}$ & 2 & 3 & 1 & 1 & 1 & 2 & 1 & 2 \\
\hline $\mathbf{F}$ & 1 & 2 & 1 & 1 & 1 & 1 & 1 & 1 \\
\hline $\mathbf{G}$ & 1 & 1 & 1 & 3 & 1 & 1 & 1 & 1 \\
\hline $\mathbf{H}$ & 1 & 3 & 1 & 1 & 1 & 1 & 1 & 1 \\
\hline I & 1 & 1 & 3 & 3 & 1 & 1 & 1 & 1 \\
\hline $\mathbf{J}$ & 1 & 3 & 1 & 1 & 1 & 1 & 1 & 2 \\
\hline $\mathbf{K}$ & 1 & 3 & 1 & 1 & 1 & 1 & 1 & 1 \\
\hline $\mathbf{L}$ & 1 & 1 & 1 & 1 & 1 & 1 & 1 & 1 \\
\hline $\mathbf{M}$ & 3 & 3 & 1 & 1 & 1 & 1 & 1 & 1 \\
\hline $\mathbf{N}$ & 1 & 3 & 1 & 2 & 1 & 1 & 1 & 1 \\
\hline
\end{tabular}




\begin{tabular}{|c|c|c|c|c|c|c|c|c|}
\hline $\mathbf{O}$ & 1 & 3 & 1 & 2 & 3 & 3 & 3 & 3 \\
\hline $\mathbf{P}$ & 1 & 1 & 1 & 1 & 1 & 1 & 1 & 1 \\
\hline $\mathbf{Q}$ & 1 & 1 & 1 & 1 & 1 & 1 & 1 & 1 \\
\hline $\mathbf{R}$ & 1 & 3 & 1 & 1 & 1 & 1 & 1 & 1 \\
\hline $\mathbf{S}$ & 1 & 2 & 1 & 1 & 1 & 1 & 1 & 1 \\
\hline $\mathbf{T}$ & 1 & 2 & 1 & 1 & 1 & 1 & 1 & 1 \\
\hline $\mathbf{U}$ & 1 & 3 & 1 & 1 & 1 & 1 & 1 & 1 \\
\hline V & 1 & 3 & 1 & 1 & 1 & 1 & 1 & 1 \\
\hline W & 1 & 1 & 1 & 1 & 1 & 1 & 1 & 1 \\
\hline $\mathbf{X}$ & 2 & 1 & 1 & 1 & 1 & 1 & 1 & 1 \\
\hline EVALU & & & & & & & & \\
\hline ASI & 358 & 638 & 31 & 36 & 32 & 340 & 33 & 252 \\
\hline CROMOS & J & 000 & 7 & 3 & 9 & 340 & 5 & 532 \\
\hline OME 1-8 & & & & & & & & \\
\hline RATA- & & & & & & & & \\
\hline RATA & & & & & & & & \\
\hline DARI & 379 & & & & & & & \\
\hline FUNGSI & & & & & & & & \\
\hline OВJEKTIF & & & & & & & & \\
\hline
\end{tabular}

\section{Seleksi Cromosome}

Proses seleksi dilakukan dengan cara membuat chromosome yang mempunyai fungsi_objektif kecil mempunyai kemungkinan terpilih yang besar atau mempunyai nilai probabilitas yang tinggi. Untuk itu dapat digunakan fungsi fitness $=(1 /(1+$ fungsi_objektif $))$, fungsi_objektif perlu ditambah 1 untuk menghindari kesalahan program yang diakibatkan pembagian oleh 0 .

Tabel 2. Seleksi Cromosome

\begin{tabular}{lllllllll}
\hline FITNE & FITNE & FITNE & FITNE & FITNE & FITNE & FITNE & FITNE & FITN \\
S 1 & S 2 & S 3 & S 4 & S 5 & S 6 & S 7 & S 8 & ES 9 \\
\hline 0,0028 & $\mathbf{0 , 0 0 1 6}$ & $\mathbf{0 , 0 0 3 1}$ & $\mathbf{0 , 0 0 2 7}$ & $\mathbf{0 , 0 0 3 0}$ & $\mathbf{0 , 0 0 2 9}$ & $\mathbf{0 , 0 0 3 0}$ & $\mathbf{0 , 0 0 2 8}$ & $\mathbf{1 , 0 0 0 0}$ \\
TOTA & $\mathbf{1 , 0 2 2 0}$ & & & & & & & \\
L & & & & & & & & \\
FITNE & & & & & & & & \\
S & & & & & & & & P8 \\
PROB & P1 & P2 & P3 & P4 & P5 & P6 & P7 & P \\
ABILI & & & & & & & & \\
TAS & & & & & & & & \\
FITNE & & & & & & & & \\
SS & & & & & & & & \\
RUMU & $\mathbf{0 , 0 0 2 7}$ & $\mathbf{0 , 0 0 1 5}$ & $\mathbf{0 , 0 0 3 1}$ & $\mathbf{0 , 0 0 2 7}$ & $\mathbf{0 , 0 0 3 0}$ & $\mathbf{0 , 0 0 2 9}$ & $\mathbf{0 , 0 0 2 9}$ & $\mathbf{0 , 0 0 2 8}$ \\
S : P[i] & & & & & & & & \\
$=$ & & & & & & & \\
fitnesS[
\end{tabular}




\begin{tabular}{lllllllll}
\hline $\begin{array}{l}\text { total_fi } \\
\text { tness }\end{array}$ & & & & & & & & \\
KOMU & C1 & C2 & C3 & C4 & C5 & C6 & C7 & C8 \\
LATIF & & & & & & & & \\
PROB & & & & & & & & \\
ABILI & & & & & & & & \\
TAS & & & & & & & & \\
& $\mathbf{0 , 0 0 2 7}$ & 0,0072 & 0,0103 & 0,0130 & 0,0130 & 0,0159 & 0,0188 & 0,0215 \\
\hline
\end{tabular}

Setelah dihitung cumulative probabilitasnya maka proses seleksi menggunakan roulete-wheel dapat dilakukan. Prosesnya adalah dengan membangkitkan bilangan acak $\mathrm{R}$ dalam range 0-1 Jika $\mathrm{R}[\mathrm{k}]<\mathrm{C}[1]$ maka pilih chromosome 1 sebagai induk, selain itu pilih chromosome ke-k sebagai induk dengan syarat $\mathrm{C}[\mathrm{k}-1]<\mathrm{R}<\mathrm{C}[\mathrm{k}]$. Kita putar roulete wheel sebanyak jumlah populasi yaitu 6 kali (bangkitkan bilangan acak R) dan pada tiap putaran, kita pilih satu chromosome untuk populasi baru. Misal seperti tabel di bawah ini.

Tabel 3. Roulete Whele

\begin{tabular}{clll}
\hline $\begin{array}{l}\text { Roulete } \\
\text { Whele }\end{array}$ & RK & $\begin{array}{l}\text { Pengujian } \\
\text { RK }\end{array}$ & $\begin{array}{l}\text { Awal } \\
\text { Populasi } \\
\text { Baru }\end{array}$ \\
\hline & & & 0,069 \\
R1 & 0,0476 & TRUE & 5 \\
R2 & 0,0842 & TRUE & \\
R3 & 0,1114 & TRUE & \\
R4 & 0,1239 & FALSE & \\
R5 & 0,1372 & TRUE & \\
R6 & 0,1642 & TRUE & \\
R7 & 0,1904 & TRUE & \\
R8 & 0,2029 & FALSE & \\
\hline
\end{tabular}

Tabel 4. Proses SeleksI

PROSES SELEKSI

\begin{tabular}{llcl} 
CROMOSOME & RK & $\begin{array}{l}\text { NILAI } \\
\text { CROMOSOME }\end{array}$ & $\begin{array}{l}\text { NILAI } \\
\text { RK }\end{array}$ \\
\hline CHROMOSOME & CHROMOSOME & 30 & 55 \\
1 & 2 & & \\
CHROMOSOME & CHROMOSOME & 55 & 55 \\
2 & 2 & & \\
CHROMOSOME & CHROMOSOME & 26 & 26 \\
3 & 3 & & \\
CHROMOSOME & CHROMOSOME & 31 & 55 \\
4 & 2 & & \\
\hline
\end{tabular}




\begin{tabular}{llll}
\hline CHROMOSOME & CHROMOSOME & & \\
5 & 2 & 26 & 26 \\
CHROMOSOME & CHROMOSOME & & \\
6 & 2 & 29 & 55 \\
CHROMOSOME & CHROMOSOME & & \\
7 & 2 & 28 & 55 \\
CHROMOSOME & CHROMOSOME & & \\
8 & 2 & 31 & 55 \\
\hline
\end{tabular}

\section{Crossover}

Setelah proses seleksi maka proses selanjutnya adalah proses crossover. Metode yang digunakan salah satunya adalah one-cut point, yaitu memilih secara acak satu posisi dalam chromosome induk kemudian saling menukar gen. Chromosome yang dijadikan induk dipilih secara acak dan jumlah chromosome yang mengalami crossover dipengaruhi oleh parameter crossover_rate $(\rho \mathrm{c})$.

Tabel 5. Proses Crossover

\begin{tabular}{cl}
\hline CROSSOVE & $\begin{array}{c}\text { Evaluasi } \\
\text { Chromosome }\end{array}$ \\
\hline CHROMOSO & \\
ME 1 & 30 \\
CHROMOSO & \\
ME 2 & 55 \\
CHROMOSO & \\
ME 3 & 26 \\
CHROMOSO & \\
ME 4 & 31 \\
CHROMOSO & \\
ME 5 & 14 \\
CHROMOSO & \\
ME 6 & 15 \\
CHROMOSO & \\
ME 7 & 16 \\
CHROMOSO & \\
ME 8 & 31 \\
\hline
\end{tabular}

\section{Mutasi Gen}

Jumlah chromosome yang mengalami mutasi dalam satu populasi ditentukan oleh parameter mutation_rate. Proses mutasi dilakukan dengan cara mengganti satu gen yang terpilih secara acak dengan suatu nilai baru yang didapat secara acak.

Tabel 6. Mutasi Gen

\section{MUTASI}




\begin{tabular}{l|l|l|l|l|l}
\hline 1. TOTAL GEN & \multicolumn{1}{|c|}{8} & & & & \\
& C4 & C5 & C6 & C7 & C8 \\
CROSS OVER & 31 & 14 & 15 & 16 & 31 \\
$\begin{array}{l}\text { 2. TOTAL MUTASI } \\
\text { PERCROMOSOME }\end{array}$ & 248 & 110 & 118 & 126 & 248 \\
\hline
\end{tabular}

Tabel 7. Rata-rata Fungsi Objective

\begin{tabular}{rc}
\hline & 4. RATA- \\
& FUNGSI \\
& OBJECTIVE \\
3.FUNGSI & SETELAH \\
OBJECTIVE & SATU \\
& GENERASI \\
& (GENERASI \\
& PERTAMA) \\
\hline
\end{tabular}

\section{CHROMOSO}

ME 2

\section{CHROMOSO}

ME 3

\section{CHROMOSO}

ME 4

CHROMOSO

ME 5

CHROMOSO

ME 6

CHROMOSO

ME 7

CHROMOSO

ME 8

Pada literasi pertama untuk proses cut maka dilanjutkan untuk proses selalnjutnya point belum menemukan kondisi pasien yang pada pengujian posisi cut point cromosome mengidap autoimun untuk kondisi false, 1-3 untuk kondisi true untuk iterasi kedua.

\begin{tabular}{lcll}
\hline & & HASIL & \\
PROSES & & PROSES & \\
SELEKSI & & SELEKSI & \\
CROMOSO & & \multicolumn{1}{c}{ NILAI } & NILAI \\
ME & RK & CROMOSOME & RK \\
\hline \hline DOI : https://doi.org/10.36341/rabit.v4i1.595 & 16 & & Penulis Pertama : Debi Setiawan
\end{tabular}




\begin{tabular}{llll}
\hline CHROMOSOME & CHROMOSOME & & \\
1 & 2 & 30 & 55 \\
CHROMOSOME & CHROMOSOME & & \\
2 & 2 & 55 & 55 \\
CHROMOSOME & CHROMOSOME & & \\
3 & 3 & 26 & 26 \\
CHROMOSOME & CHROMOSOME & & \\
4 & 2 & & \\
CHROMOSOME & CHROMOSOME & & \\
5 & 2 & & \\
CHROMOSOME & CHROMOSOME & \\
6 & 2 & & \\
CHROMOSOME & CHROMOSOME & \\
7 & 2 & \\
CHROMOSOME & CHROMOSOME & \\
8 & 2 & \\
\hline
\end{tabular}

Lakukan proses pemutaran kromosome

1. Tentukan nilai cromosome terkecil $=2$

2. Tentukan nilai cromosome terbesar $=5$

3. Masukan nilai cromosome, ketabel nilai cromosome sesuai urutan
4. Untuk nilai rk, berpedoman pada nilai cromosome, jika nilai cromosome $>$ maka untuk nilai rk diisi dengan 26, jika nilai cromosme $<=$ maka diisi dengan 5 .

Tabel 9. Nilai Crossover

\begin{tabular}{|c|c|c|}
\hline & CROSSOVER & Nilai \\
\hline \multicolumn{3}{|c|}{ CHROMOSOME } \\
\hline 1 & & 30 \\
\hline & CHROMOSOME & \\
\hline 2 & & 55 \\
\hline & CHROMOSOME & \\
\hline 3 & & 26 \\
\hline & CHROMOSOME & \\
\hline 4 & & \\
\hline & CHROMOSOME & \\
\hline 5 & & \\
\hline & CHROMOSOME & \\
\hline 6 & & \\
\hline & CHROMOSOME & \\
\hline 7 & & \\
\hline & CHROMOSOME & \\
\hline 8 & & \\
\hline
\end{tabular}

Tabel 10. Mutasi Iterasi ke-2 


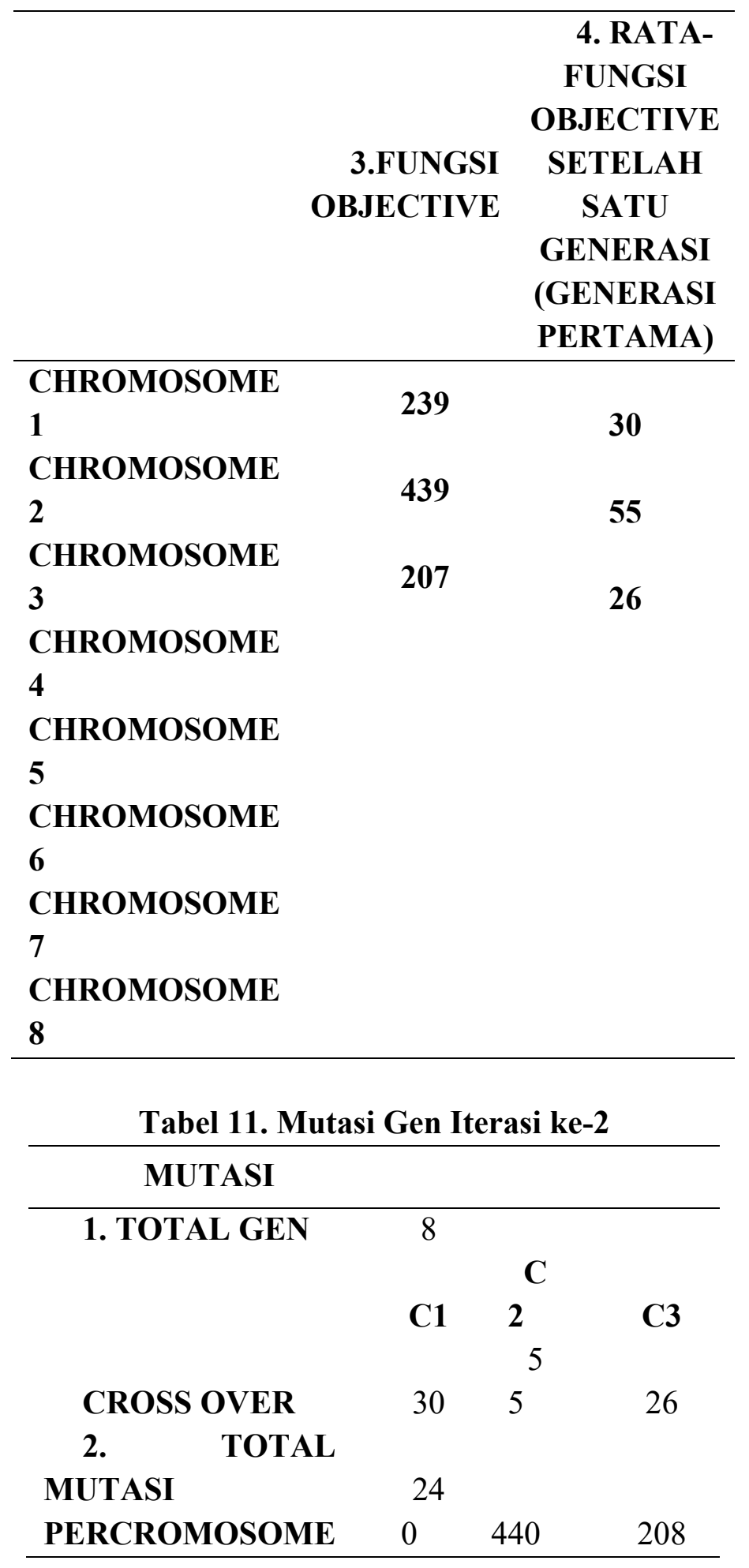

\section{KESIMPULAN}

Algoritma genetika mampu melakukan prediksi penyakit autoimun pada iterasi pertama hal ini sudah terlihat dengan nilai
14.88 yang diambil dari proses algortima genetika dengan persamaan $\mathrm{f}=$ $\mathrm{a}+2 \mathrm{~b}+3 \mathrm{c}+4 \mathrm{~d} \ldots 24 \mathrm{x}<=17$. Pada penelitian ini model algoritma yang dikembangkan 
baru pada iterasi pertama, untuk hasil yang optimal perlu dilakukan perulangan iterasi. Penelitian ini nanti akan dikembangkan untuk dimplementasikan pada aplikasi sehingga dapat membantu dokter spesialis penyakit dalam untuk mendiagnosa pasien apakah terindentifikasi penyakit autoimun.

\section{DAFTAR PUSTAKA}

[1] PUSDATIN, Infodatin-Lupus2017.pdf. 2017.

[2] Diantini, Ulandari, Wirandani, Niruti, and Kumara, "ANGKA KEJADIAN PENYAKIT AUTOIMUN PADA PASIEN ANAK DI RSUP SANGLAH DENPASAR," J. Farm. Udayana, vol. 5, no. 2, pp. 30-34, 2016.

[3] T Sutojo, Kecerdasan Buatan. 2011.

[4] Rino, "Penerapan Metode Neural Network Berbasis Algoritma
Genetika Untuk Prediksi Penyakit Kanker Payudara," vol. 1, pp. 1-11, 2012.

[5] K. Krisnandi, H. Agung, P. Studi, T. Informatika, F. Teknologi, and U. B. Mulia, "Implementasi Algoritma Genetika untuk Memprediksi Waktu dan Biaya Pengerjaan Proyek Konstruksi," vol. IX, no. 2, pp. 9097, 2017.

[6] D. C. P. Buani, "Optimasi Algoritma Naïve Bayes dengan Menggunakan Algoritma Genetika untuk Prediksi Kesuburan (Fertility)," Evolusi, vol. 4, no. 1, pp. 54-63, 2016.

[7] K. Dewi, Penyelesaian Masalah Optimasi Dengan Teknik-Teknik Heuristik. Graha Ilmu, 2003. 